\title{
Euler zirkuluen erabilera intentsionalak silogistika kategorikorako
}

\author{
IBON COTERÓN
}

IES Ategorri BHI

\section{(Intensional uses of Euler circles for categorical syllogistics)}

DOI: $10.1387 /$ gogoa.20359

\begin{abstract}
In this article I propose a pair of intensionally interpretable systems of Euler circles for categorical syllogistics that fit perfectly with the original Aristotelian system, and represent in a direct and intuitive manner the existential import that is needed for the validity of some syllogistic modes. At the same time, the original intuitiveness of the Eulerian representations for universal propositions is expanded to the representation of particular propositions, because both the crosscutting of circles and the ad hoc marking of existent entities may and will be avoided.
\end{abstract}

Keywords: diagrammatic logic, categorical syllogistics, Euler circles.

\section{Laburpena}

Artikulu honetan proposatuko ditut intentsionalki interpreta daitezkeen Euler zirkuluen sistema bi. Ikusiko denez, sistemok zehatz-mehatz egokitzen dira Aristotelesen jatorrizko sistemarekin eta modu artezean eta intuitiboan irudikatzen dute onartze existentziala, zeina zenbait modu silogistikok baliodun izateko behar duten. Aldi berean, proposizio partikularren irudikatzeetara ere hedatzen da proposizio unibertsalen eulertar irudikatzeek duten jatorrizko intuitibotasuna, zeren eta alboratu egiten baitira zirkuluak ebakitzea eta existitzen diren izakiak ad hoc markatzea.

Gako-hitzak: logika diagramatikoa, silogistika kategorikoa, Euler zirkuluak. 


\section{Hitzaurrea}

Gogoangarria. Horixe da niretzat gure Jesus Mari: Jesus Mari Larrazabal Antia gogoangarria. Zalantzarik gabe, gutako askoren bizitza akademikoan ezabaezina izango da haren aztarna. Nire kasua ez da salbuespena. Oso bestelakoa litzateke ene pentsamoldea Jesus Mariren eragina jasotzen hasi ez banintz duela 25 urte inguru haren gidaritzapeko doktoregorako biurteko bikain batean. Ez nukeen garatuko ene ikerkuntza-lan apala haren ekinari esker sortutako ILCLIren babesagatik izan ez balitz. Ezin gusturago parte hartu nahi izan dut haren omenezko Gogoaren ale honetan, eta horretarako hausnarketa logiko bat egokiena delakoan nago. Logikaren aldameneko alderdi baten inguruan bada ere, espero dut haren gustukoa izatea.

\section{Sarrera}

Sato eta bestek (2010: 6) seinalatu dutenez, bai Euler, bai Venn diagramak «biziki ikasi dira logika diagramatiko formalean 1990etatik». ${ }^{1}$ Lan horren erakusleiho bat eskaintzen du Stapletonek (2005); ikus, halaber, Pagnan (2013). Bestelako ikerketa-lerro bat, enpirikoa, arduratu da errepresentazio- eta arrazoiketa-metodo diagramatiko horien oinarri kognitiboez (ikus, esaterako, Mineshima eta beste 2008, Sato eta beste 2010, Sato eta beste 2011, Sato 2013). Euler zirkuluen aurreko erabilerek (Gergonneren 1817ko bertsioan oinarrituek), zenbait premisaren errepresentaziorako, «konbinazio-leherketa» baten aurrean ipintzen zuten erabiltzailea (Johnson-Laird 1983, ikus 1. irudia).
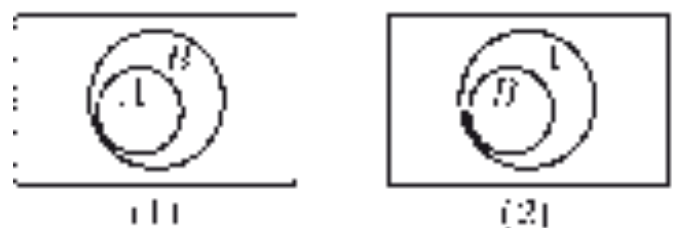

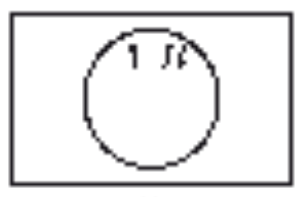

$\because 1$

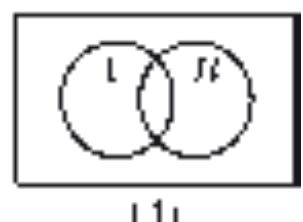

| 1 |

\section{1. irudia}

Sato 2013tik egokitua:

Ohiko Gergonne diagramak, «A batzuk B dira» irudikatzeko

Bestelako proposamen formalizatuek, aldiz, bide bat eskaintzen dute kasu orotan errepresentazio sinpleak eskuratzeko. Halako bat dugu EUL (Mineshima eta beste 2012). Horretarako nahikoa da «ebakitzearen konbentzioa» (Sato 2013), era ez-formalean esanik: kontrako informaziorik izan ezean, marraztu edozein zirkulu berri aurreko zirkulu guztiak ebakiz. Proze-

\footnotetext{
1 «Have been intensively studied in formal diagrammatic logic since. the 1990s.» (Sato eta beste 2010: 6)
} 
dura horren azpiko ideia hau da: zehaztugabea dela partzialki gainjarritako zirkuluen arteko harreman semantikoa. ${ }^{2} 2$. irudiak erakusten du nola irudikatzen diren EUL sisteman eta Venn diagramen ohiko erabileran lau proposizio kategorikoak: 1) A guztiak B dira (notazio laburtuan $A a b$ ); 2) A bat ere ez da B $(E a b)$; 3) A batzuk B dira $(I a b)$; 4) A batzuk ez dira B $(O a b)$. Aldea proposizio unibertsalei dagokie $(1,2)$ : erabateko inklusioa edo esklusioa artez marrazten da EUL sisteman, hutsik dagoen aldea ilunduz Venn diagramenean.
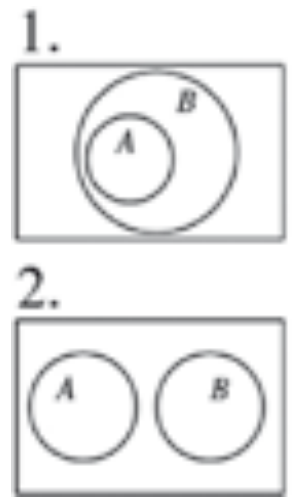

3.
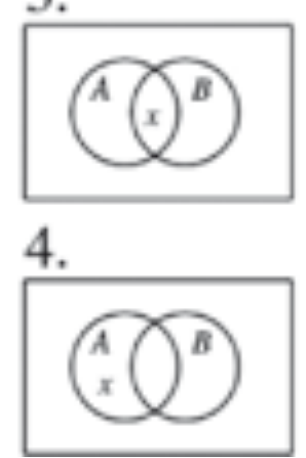
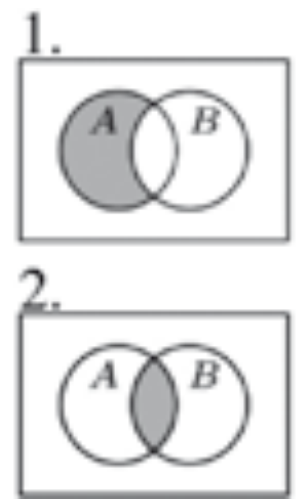

3.
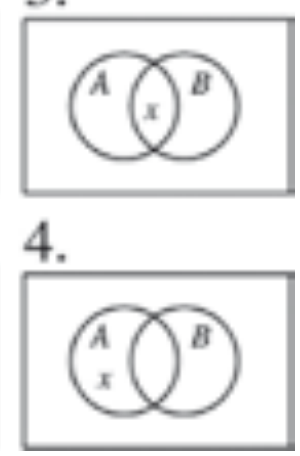

2. irudia

Sato eta beste 2011tik hartua

Esperimentu ugarik (Mineshima eta beste 2008, Sato eta beste 2010, Sato eta beste 2011, Sato 2013) erakutsi dute ezen, premisa eta ondorio unibertsalak jokoan dauden heinean, denbora gehiago behar dugula Venn diagrama bat prozesatzeko silogismo beraren EUL errepresentazioa prozesatzeko baino (3. irudiko 1-6 diagramak). Halako aldeek desagertzera jotzen dute premisa partikularrak jokoan sartzen direnean (3. irudiko 7-11 diagramak), zeren eta sistema bietan bide berdinez irudikatzen baitira (gurutze bat item baten existentzia markatuz zirkulu baten barruan eta aurrekoa ebakitzen duen beste zirkulu baten barruan edo kanpoan).

EULen nahita bilaturiko abantaila bat honako hau da: ez duela erabiltzen bestelako sistemetan ohikoa den «onartze existentziala». Onartze hori aurki daiteke Gergonneren sistemaren modukoetan, baina baita bestelakoetan ere, hala nola Stenning eta Oberlanderrenean (1995), aurrerantzean S-O sistema. Hori ere, bestalde, gai zen «lehertze esponentziala» eragozteko eta zatikako informazioa (nahiz informazio disjuntiboa) diagrama bakar batean irudikatzeko. Sistema horretan, zatiketarik gabeko zirkulu orotan gurutze bat jartzen da hutsik ez dagoela adierazteko, baina gurutzea ezabatu egiten da zirkuluan

\footnotetext{
2 Puntu hau, hala ere, sistemaren ahuleziatzat har daiteke haren intuitibotasunari begira. Satok (2013) onartu duenez, subjektu esperimentalen kopuru handi batek jotzen du pentsatzera horrela ebakitako zirkuluen sektore guztietan badagoela izakiren bat gutxienez.
} 
zatiketarik ezarri bezain pronto (diagramak bateratzearen ondorioz). Aldiz, proposizio partikularrak irudikatzen dituzten gurutzeak ez dira ezabatzen.

EUL eta S-O sistemen arteko aldea argitu egiten da haien bidez irudikatuz gero zenbait modu silogistiko, horiek zeintzuek ondoriorik eskuratzeko onartze existentziala behar duten, hain zuzen. Horren adibide dugu Felapton modua: $E b c, A b a$, beraz $O a c$
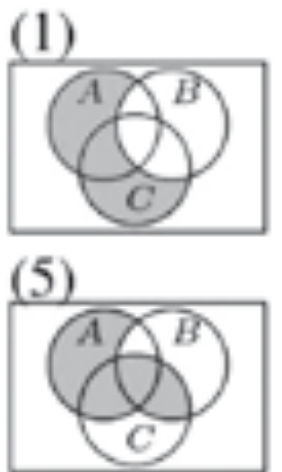

(9)

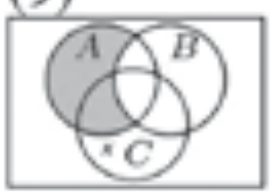

(1)

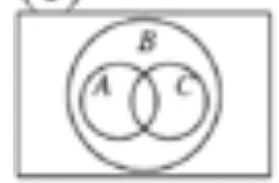

(5)

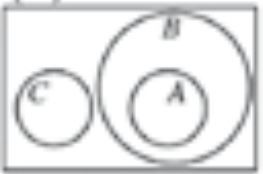

(9)

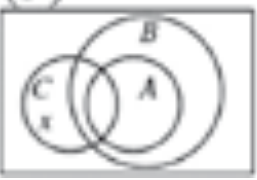

(2)

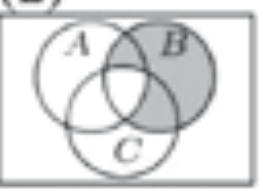

(6)

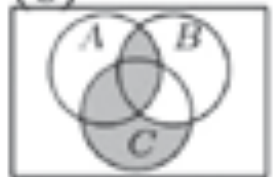

\section{(10)}

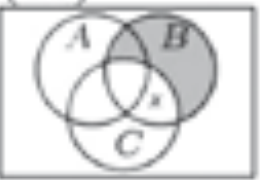

(2)

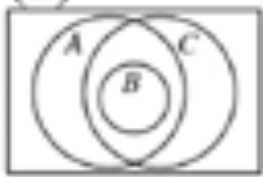

(6)

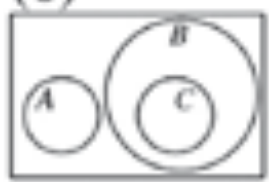

(10)

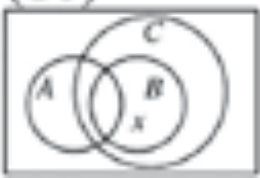

\section{3. irudia}

(3)

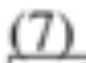

(3)

(7)
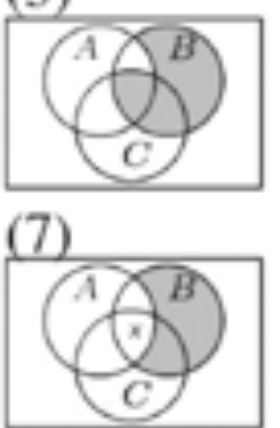

(11)
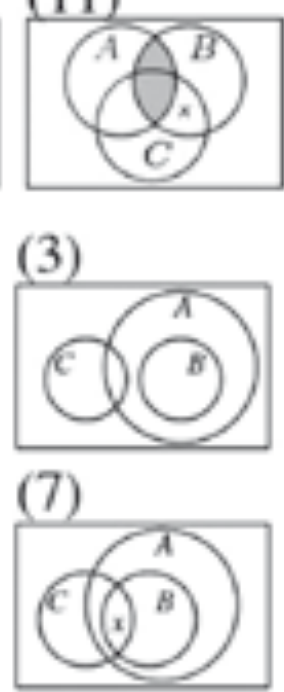

(11)

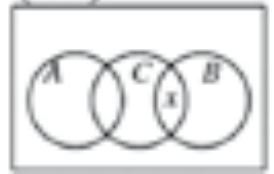

(4)

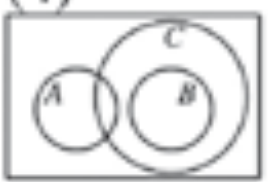

(8)

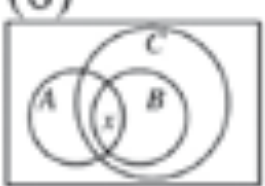

Sato eta beste 2011tik egokitua

Modu horren EUL diagrama bateratua 3. irudiko 3.a da, eta ez da bertatik inolako ondoriorik ateratzen. Dagokion S-O diagrama bateratua antzekoa da, 
baina gurutze bat mantentzen da B etiketadun zirkuluaren barruan, eta horrek ahalbidetzen digu Oac ondorio partikularra ateratzea.

Guztiz desberdina da hurrengo ataletan aurkeztuko dudan hurbilketa. Aurrekoak ez bezala, Euler zirkuluen erabilera intentsionalean oinarrituko $\mathrm{da}$, eta artez irudikatuko ditu onartze existentzialaren zenbait kasu, baina beste batzuk ez, eta guztiz bat etorriko da Aristotelesen jatorrizko silogistika kategorikoaren sistemarekin.

\section{Badago Euler zirkuluak intentsionalki erabiltzea}

Orain arte ikusitako hurbilketa guztiak estentsionalak dira: objektuek eta objektu multzoek edo klaseek betetzen dute planoak irudikatutako espazio semantikoa. Arreta gutxi, edo batere ez, eskaini zaio beste aukera honi: Euler zirkuluak intentsionalki erabiltzeari, kontzeptuen arteko harremanak irudikatuz. Holako trataera baten posibilitatea bera ukatu zuen Couturatek (1961). Basslerrek (1998) defenditu egin zuen, baina nola gauzatu erakutsi gabe. Ideiaren aldeko sostengua hemen aurki daiteke: Satok (2013) erakutsi du EULen sistema parekide bat eraiki daitekeela diagrama linealak erabiliz. Bestalde, Basslerrek (1998) seinalatu duenez, Leibnizek berak erabilitako antzeko diagrama batzuk intentsionalki irakur daitezke. Ondorioz, merezi du kontuan hartzea eulertar sistema intentsional baten posibilitatea. Sistema horretan erabiliko lirateke inklusio- eta esklusio-harreman intuitiboki argiak bakarrik; baztertu egingo lirateke bai zirkuluen ebaketa, baita ebakitzearen konbentzioa ere.

\section{Kontzeptuen arteko inklusio-harremanak irudikatzen}

Ongi jakina denez (Bassler 1998), halako trataera batean alderantziz jarri behar da inklusio-erlazioa:

\begin{tabular}{|c|c|c|}
\hline & Trataera estentsionala & Trataera intentsionala \\
\hline $\begin{array}{c}x \text { guztiak } \\
y \text { dira } \\
(A x y)\end{array}$ & «X multzoa / klasea y multzoaren / & «X kontzeptuak (beti) hartzen du \\
\hline
\end{tabular}

4. irudia 
Nola eragotzi diagrama intentsionalaren ohiko irakurketa estentsionala? Horretarako ideia ona dirudi nolabait markatzeak ezen barruko zirkuluak ez duela irudikatzen kontzeptu hori bere osotasunean (beste zenbait kontzepturen barruan ere ager daiteke, haien osagai gisa), baizik eta kanpoko zirkuluak sinbolizaturiko kontzeptura hedatzen dela eta hura tindatzen duela. Zentzu horretan, barruko zirkuluak lerro eten batez marraztuko dira.

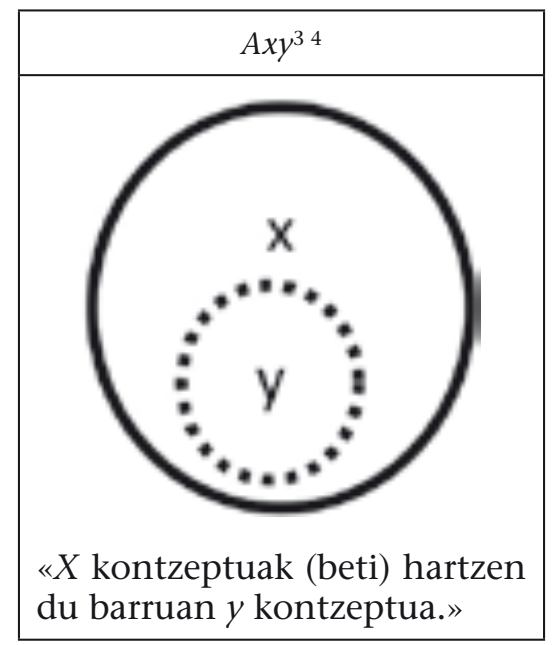

\section{5. irudia}

Horren arabera, erraza da irudikatzea Darapti modu klasikoaren premisa biak (Amx, Amy).

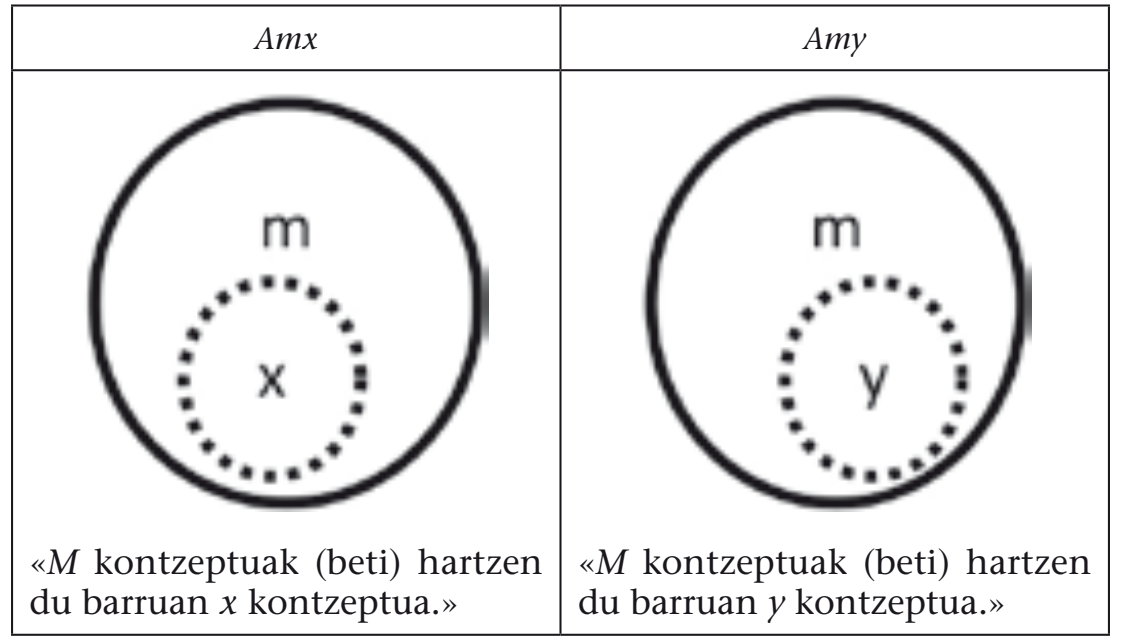

6. irudia

\footnotetext{
${ }^{3}$ Irudikatze horrek adieraz dezake bai $A x y$, bai haren zatikako inbertsioa nahiz bihurtze per accidens den Iyx («y batzuk $x$ dira»). Segidan ulertuko da interpretazio bikoitzaren zergatia, hau ikusten denean: 5. irudia 8. irudiaren kasu berezia baino ez dela.

${ }^{4}$ Honela berridatz dezakegu eskematikoki halako diagrama: $\left\{{ }_{\mathrm{x}}(\mathrm{y})_{\mathrm{x}}\right\}$.
} 
Diagrama biak bateratzeko nahikoa da arau hau aplikatzea: etiketa bereko zirkuluak bat egin daitezke, baldin diagrametako batean gutxienez marra jarraituaz agertzen bada.

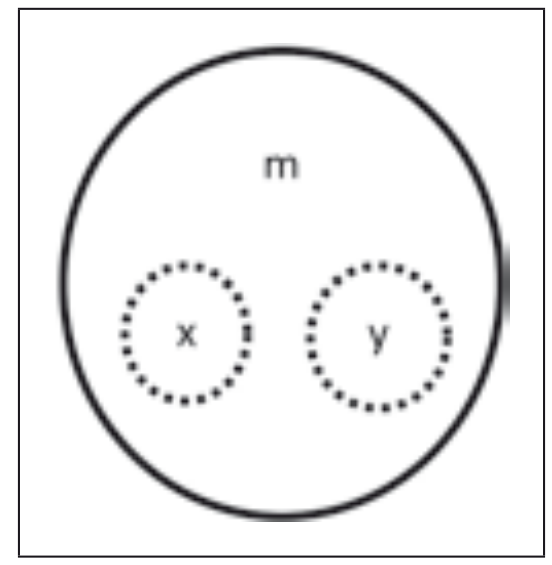

7. irudia $^{5}$

Beste arau batek ahalbidetuko digu ezabatzea (edo, besterik gabe, kontuan ez hartzea) termino errepikatua $(m)$ :

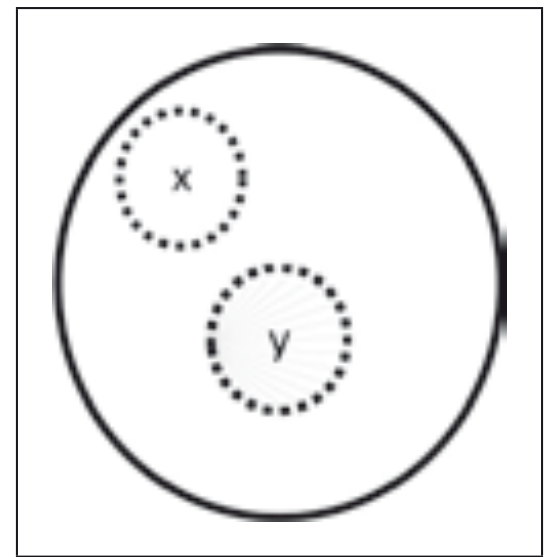

8. irudia $^{6}$

Diagrama horrek egokiro irudikatzen ditu Ixy eta $I y x$ ondorioak ( $«$ batzuk $y$ dira» eta «y batzuk $x$ dira»), hau adieraziz: ikuspegi intentsionaletik,

5 Eskematikoki: $\left\{{ }_{\mathrm{m}}(\mathrm{x})(\mathrm{y})_{\mathrm{m}}\right\}$.

${ }^{6}$ Hots: $\{(\mathrm{x})(\mathrm{y})\}$. 
proposizio horiek bat datoz zera esatearekin, badagoela kontzepturen bat (etiketarik gabekoa, beharbada) zeinak barruan hartzen baititu bai $x$, bai $y$. Goragoko (intentsionalki estuagoa den) kontzeptu hura da, hain zuzen, bitartekaria barruragoko (intentsionalki zabalagoak diren) beste kontzeptu bien artean. Ondorioz, sistemarentzat funtsezkoa da 6. irudiko diagramen irakurketa bikoitza (Amx eta Ixm, Amy eta Iym).

Nola irudika ditzakegu ezezko proposizioak, Exy ( «x bat ere ez da $y »)$ eta Oxy («x batzuk ez dira $y »)$ ? Bide bi daude horretarako, eta ondoko atal bietan azalduko dira.

\section{Kontzeptu negatiboen inklusioa erabiliz: «OIL» deritzodan sistema}

Izan bedi edozein kontzeptu, $m$ esaterako, baldin erabiltzerik badugu haren ordain negatiboa $(m)$, orduan ez dugu bestelako diagramarik behar ezezko proposizioetarako. Obertsioaz, ezezko edozein proposizio baiezko bihur daiteke jatorrizko predikatuaren ordez haren ordain negatiboa jarriz: $E x y=A x y, O x y=I x y$. Ziurtatu behar dugu prozedura honen bidez erdiko terminoa ez dela ezabatzen (premisa batean $\mathrm{m}$ eta bestean $\mathrm{m}$ izanik). Horretarako, bihurtze-arau tradizionalok erabili behar ditugu: bihurtze sinplea $(E x y=E y x, I x y=I y x)$ eta kontrajartzea $(A x y=A y x, O x y=O y x)$.

Kontzeptuen ordain negatiboen erabilera onartu bezain pronto, kontsistentzia-arau bat behar dugu: kontzeptu batek ere ezin barnera dezake bere «ukazioa» (zirkulu bat ere ezin da batera etiketatu $m$ gisa eta, barruko zirkuluengatik, $m$ gisa ere bai). Bestela esanik: halako etiketatze bikoitza lukeen edozein kontzeptu hustu eta desagertu egingo litzateke.

Hori da behar den guztia honako hauek ateratzeko: (i) modu aristoteliko baliodunen ondorio zuzenak (haien artean izanik geroago 4. irudi silogistikoan sartu ziren zeharkako moduak, baina ez menpeko moduak); baita (ii) logikari modernoek (subjektu negatiboak erabiliz) proposaturiko beste zenbait modurenak ere; eta (iii) ondorio oker bat ere ez.

OIL sistemaren konplexutasuna analizatzearren, alde bi bereizi behar ditugu bertan: alde diagramatikoa eta arau multzo bat (ezezko proposizioen eta obertsioaren bidezko haien baliokideen arteko itzulpenerakoa).

Alde diagramatikoaren osagaiak hauek dira: planoa, kontzeptuak etiketatzeko erabilitako letrak (eta konbentzio bat, kontzeptu bat beste baten ordain negatibo gisa markatzeko), eta bi zirkulu mota (marra jarraituduna eta marra etenduna). Alde diagramatiko horren sintaxia eta semantika xaloak dira oso: kontzeptuak planoan irudikatzen dira zirkuluen bidez, etiketa batekin edo halakorik gabe; premisa biei dagozkien diagramak bateratzen dira etiketa bereko zirkuluak bat etorraraziz, baldin diagrametako batean (edo bietan) 
haien zirkunferentziako marra jarraitua bada. Ondorioa irakurtzeko nahikoa da kontuan ez hartzea errepikaturiko etiketa. Ez da onartzen zirkuluen ebaketarik. Ezin da irudikatu informazio zehaztugaberik: harreman zehaztugabeek geldiarazi egiten dute diagramen bateratzea.

Itzulpen-tresneria arrunta da, baina kontuan hartzeko moduko konplexutasuna gehitzen dio sistemari. Hura kalkulatu beharrean, azter dezagun nola erabili sistema halakorik gabe. Nahikoa da ezartzea proposizio unibertsal bat irudikatzeko badaudela bi diagrama posible (inoiz interpretazio zailekoak), ${ }^{7}$ eta erabiltzaileak haien artean erabaki behar duela. Praktikan, ondorioztatze gehienak erraz bidera daitezke erdiko terminoa edo termino errepikatua $(m)$ aldatu gabe lagaz (esaterako, Exm Am* gisa itzuliz, ez Axm gisa). Salbuespena sortzen da premisa bat Oym formakoa denean, beraz Iym. Halakoetan, baldin beste premisa Exm (edo Emx) bada, hori itzuli behar da Axm gisa (baina diagramak ezin batera daitezke eta, zuzenki, ez dago ondoriorik), eta baldin beste premisa Axm bada, hori Amx bihurtu behar da, non $I y *$ ondorio zuzena eskuratzen den. Hala ere, sisteman Subjektu-Predikatu bereizketak eragina duenez, batzuetan beharrezkoa da $m$ biak bihurtzea, modu silogistikoa balioduna dela erakutsiko bada. Har dezagun, esaterako, Apm eta Ems premisa multzoa. Artez irudika ditzakegu Apm eta Ams $\left(\left\{_{\mathrm{p}}(\mathrm{m})_{\mathrm{p}}\right\}\right.$ eta $\left.\left\{_{\mathrm{m}}(\mathrm{s})_{\mathrm{m}}\right\}\right)$ gisa. Horrek Eps ondoriora bideratzen gaitu haren $\operatorname{Aps}\left(\left\{_{\mathrm{p}}\{(\mathrm{s})\}_{\mathrm{p}}\right\}\right)$ forman, baina ez digu ematen haren baliokidea den Esp ondorioa Asp-ren bitartez. Aldiz, ondorio hori (Camenes modu baliodunari dagokiona) eskuragarri dago baldin Apm bihurtzen bada Amp eta Ems bilakatzen bada Asm, zeren $\left\{_{\mathrm{m}}(\mathrm{p}){ }_{\mathrm{m}}\right\}$ eta $\left\{_{\mathrm{s}}(\mathrm{m}){ }_{\mathrm{s}}\right\}$ bateratuz $\left\{_{\mathrm{s}}\{(\mathrm{p})\}_{\mathrm{s}}\right\}$ lortzen baita.

Ondorioz, OIL sistemak ezin ordezka dezake silogistikarekiko hurbilketa tradizionalago bat, baina balio dezake haren osagarri gisa. Edonola ere, badago bestelako bide bat ikertu beharrekoa.

7 Hauek dira Exyrako aukera biak: $\left\{_{\mathrm{x}}(\mathrm{y})_{\mathrm{x}}\right\}$ eta $\left\{_{\mathrm{y}}(\mathrm{x}){ }_{\mathrm{y}}\right\}$. Besteok dira Axyrako aukerak: $\left\{_{\mathrm{x}}(\mathrm{y}){ }_{\mathrm{x}}\right\}$ eta $\left\{y(*){ }_{y}\right\}$. 


\section{Ezezko proposizioen irudikatze intentsionala: «OILER» deritzodan sistema}

Honela irudika daitezke ezezko proposizioak:

$$
\text { Exy, Eyx }
$$

«X kontzeptuak ez du (inoiz) barruan hartzen $y$ kontzeptua, eta ez da (inoiz) haren barruan hartua.»

« $Y$ kontzeptuak ez du (inoiz) barruan hartzen $x$ kontzeptua, eta ez da (inoiz) haren barruan hartua.» « $X$ eta $y$ kontzeptuek elkar alderatzen dute.»

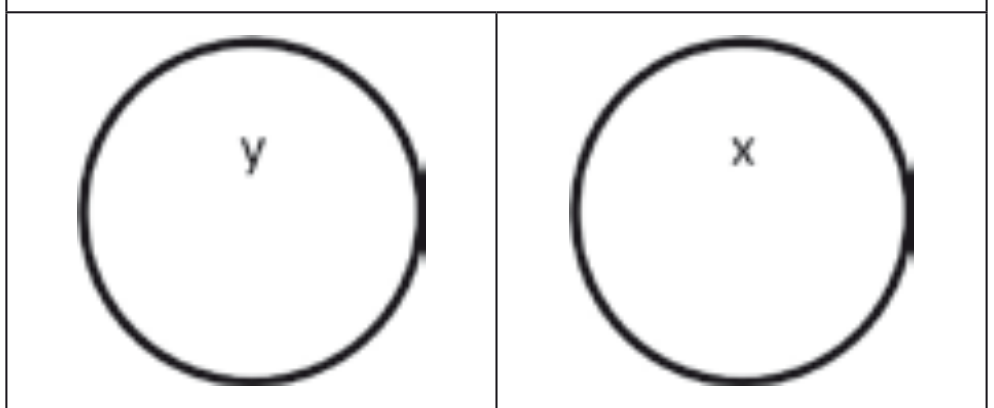

9. irudia

Elkar ebakitzen ez duten zirkuluak ez lirateke aski ideia horren irudikatze egokirako. Ezinbestekoa da erdiko marra, zeina ezin zeharka daitekeen, baztertu behar baita posibilitate hau: hirugarren kontzeptu batek (etiketarik gabekoa, apika) diagramako biak barruan har litzan. Baztertu egin behar da Exy/Eyx kontraesanean dagoelako Ixy/Iyxrekin. Irudikatze eskematikorako honelako zerbait erabil dezakegu: $\{\mathrm{x}\}][\{\mathrm{y}\}$.

Horren antzera:

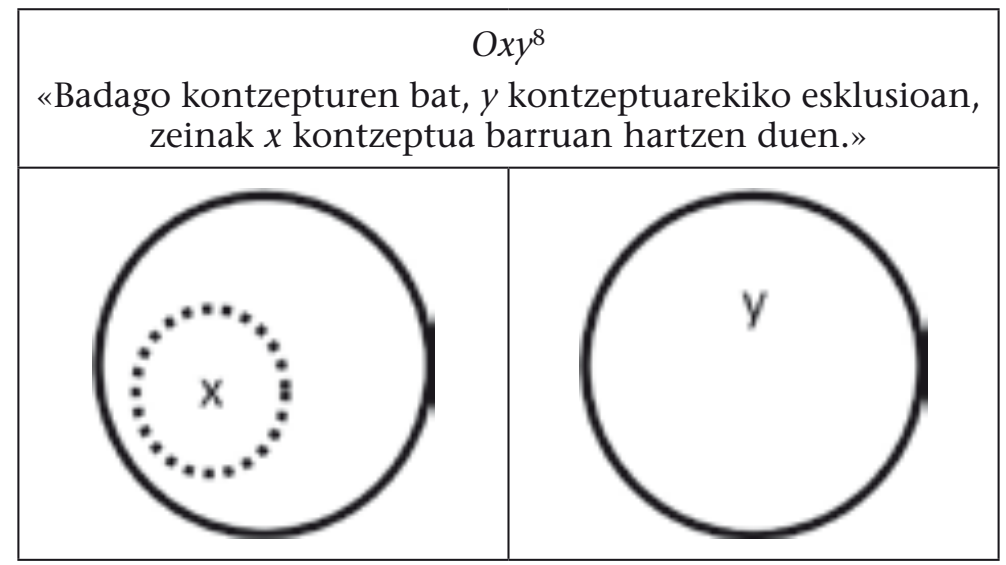

10. irudia

8 Barruko zirkulua, diagramak bateratu ondoren, lerro jarraituaz markaturik ager daiteke, baina, hala ere, ezezko proposizio partikularra $(O)$ sinbolizatuko litzateke. 
Eskematikoki: $\{(\mathrm{x})\}][$ y $\}$.

Sistema hau (OILER) askoz sinpleagoa da aurreko sistema (OIL) baino, zeren falta baitzaio itzulpen-arau multzo konplexua eta gutxi gehitzen baitio alde diagramatikoari: muga bat baino ez elkarrekiko esklusiboak diren kontzeptuen artean. Arauek bermatzen dute ezin batera daitezkeela ez premisa partikular bien irudikatzeak, ezta ezezko premisa bienak ere. OILER, jakina, ez da OIL bezain ahaltsua. Ez du balio zenbait ondorio eskuratzeko subjektu negatiboko premisetatik (esaterako: Omx, Emy, beraz bai Oxy, baita $O \forall x$ ere). Hortik kanpo, irudika ditzake tradizioaren modu artez guztiak, baita «onartze existentziala» behar omen dutenak ere: Darapti (Amy, Amx, beraz Ixy nahiz Iyx), Felapton (Emy, Amx, beraz Oxy), Bamalip (Aym, Amx, beraz Ixy) eta Fesapo (Eym, Amx, beraz Oxy). OIL sistemarekin gertatzen zen bezalaxe, ezin irudika ditzake menpeko moduak: Barbari (Amy, Axm, beraz Ixy), Celaront (Emy, Axm, beraz Oxy), Cesaro (Eym, Axm, beraz Oxy), Camestrop (Aym, Exm, beraz Oxy) eta Camenop (Aym, Emx, beraz Oxy). Horrek esan nahi du alde handia dagoela onartze existentzial bion artean: Axytik Iyxra bihurtze per accidens delakoari esker daramana (sistemak ezin irudika dezake antzeko zerbait Exytik Oyxra), eta menpekotasunari zor zaiona (Axytik Ixyra). ${ }^{9}$ OIL eta OILER sistemek berez adierazten dute alde hori, trataera estentsionalek ez bezala: halakorik ez da berez adierazten ez Venn diagramen bidez, ${ }^{10}$ ezta S-O eulertar sisteman ere. Baita neutralagoa den SYLL formalismoak (Pagnan 2013) ere, zeinak irakurketa estentsionala zein intentsionala ametitzen duen, prozedura bera erabiltzen du premisa unibertsal bitatik ondorio partikularra ematen duten modu silogistiko guztientzat: premisa existentzial bat itsastea. Hala ere, aldaketa txiki bat proposa daiteke ${ }^{11}$ SYLL sisteman, ia OILER bezain hurbila izan dakion silogistika aristotelikoari. Ondoko atalaren gaia izango da hori.

\footnotetext{
9 Aldea dagokio solas-inplikaturaren bidez ondoriozta daitekeenari: demagun badakidala egia direla bai $A x y$, bai $I y x$; baldin badiotsut badakidala Iyx egia dela, besterik ez, aditzera ematen dizut ez dakidala ezer informatiboagorik, hala nola $A x y$. Iyxtik, solas-inplikaturaren bidez, pentsa dezakezu (beharbada okerki) Oyx ere egia dela, eta hor bukatzen da kontua. Baina demagun egiatzat ditudala bai $A x y$, bai Ixy, eta azkena soilik jakinarazten dizudala. Kasu horretan, solas-inplikaturaren bidez, ondoriozta dezakezu Oxy ere egia dela, baina hori kontraesanean dago Axyrekin.

10 Badago bide erraz bat halako onartze existentziala irudikatzeko Venn diagramak erabiliz, ondoko araua aplikatzea: baldin zirkulu baten lau sektoreetatik hiru hutsik badaude, markatu laugarrenean zerbait badagoela. Prozedura horrek, hala ere, ez du bereizten Bamalip eta Barbari moduen artean.

11 Izan ere, 1. batxilergoko ikasle batek iradoki zidan.
} 


\section{Erkaketa SYLL «kalkulu diagramatikoarekin»}

SYLL baliatzen da geziez $(\rightarrow, \leftarrow)$, puntuez $(\bullet)$, eta letrez, azken horiek termino silogistikoen etiketa gisa $(A, B, C \ldots)$. Honela irudikatzen dira proposizio kategorikoak:
$A b c$ :
bai $\mathrm{B} \rightarrow \mathrm{C}$
bai $\mathrm{C} \leftarrow \mathrm{B}$
$E b c, E c b: \quad$ bai $\mathrm{B} \rightarrow \bullet \leftarrow \mathrm{C}$
bai $\mathrm{C} \rightarrow \bullet \leftarrow \mathrm{B}^{12}$
$I b c, I c b$ :
bai $\mathrm{B} \leftarrow \bullet \rightarrow \mathrm{C}$
bai $\mathrm{C} \leftarrow \bullet \rightarrow \mathrm{B}$
$\mathrm{Obc}$ :
bai $\mathrm{B} \leftarrow \bullet \rightarrow \bullet \leftarrow \mathrm{C}$
bai $\mathrm{C} \rightarrow \bullet \leftarrow \bullet \rightarrow \mathrm{B}$

Premisak erdiko terminoaren bidez lotzen dira, adibidez:

$$
\underline{\mathrm{B} \rightarrow \mathrm{C} \quad \mathrm{C} \rightarrow \bullet \leftarrow \mathrm{D}}
$$

Ondorioa ateratzeko nahikoa da sinplifikatze-arau bat: $\rightarrow \mathrm{C} \rightarrow$ bilakatzen $\mathrm{da} \rightarrow$, eta $\leftarrow \mathrm{C} \leftarrow$ bilakatzen $\mathrm{da} \leftarrow$.

Zenbait pertsonak intuizioaren kontrakotzat jotzen dukete puntu beltzaren esanahia, ez baitu inolako izaki edo kontzepturik irudikatzen, baliabide formal hutsa izanik, baina oso erraza da sistema erabiltzea. Edonola ere, onartze existentziala behar duen edozein ondorio lortzeko, prozedura bera erabiltzen da: terminoetakoren bati dagokion proposizio existentzial bat gehitzea: $\mathrm{C} \leftarrow \bullet \rightarrow \mathrm{C}$. Prozedura horrek ezkutatzen du garrantzizko alde bat, zeina erakuts daitekeen Barbari/Bamalip eta Darapti moduak konparatuz:

Barbari: Amp, Asm, beraz Isp. / Bamalip: Amp, Asm, beraz Ips.

$$
\frac{\mathrm{P} M \quad \mathrm{M} \leftarrow \mathrm{S}}{\frac{\mathrm{P} \leftarrow \mathrm{M} \leftarrow \mathrm{S}}{\mathrm{P} \leftarrow \mathrm{S}}}
$$

Berez eskuratzen dugun ondorioa $A s p$ da, ez inolako ondorio partikularra. Halakorik lortzeko ezinbestekoa da honako premisa ad hoc gehitzea: $\mathrm{S} \leftarrow \bullet \rightarrow \mathrm{S}$. Errepika dezagun ondorioztapena hura kontuan hartuz:

$$
\begin{gathered}
\frac{\mathrm{P} \leftarrow \mathrm{M}}{\mathrm{M} \leftarrow \mathrm{S}} \mathrm{S \leftarrow \bullet \rightarrow S} \\
\frac{\mathrm{P} \leftarrow \mathrm{M} \leftarrow \mathrm{S} \quad \mathrm{S} \leftarrow \bullet \rightarrow \mathrm{S}}{\mathrm{P} \leftarrow \mathrm{S} \quad \mathrm{S} \bullet \bullet \mathrm{S}} \\
\frac{\mathrm{P} \leftarrow \mathrm{S} \bullet \bullet \mathrm{S}}{\mathrm{P} \leftarrow \bullet \rightarrow \mathrm{S}}
\end{gathered}
$$

12 Hori horrela da zeren B $\rightarrow \bullet($ edo $\bullet \leftarrow$ B) bidez irudikatzen da B multzoaren osagarria, edo B kontzeptuaren ordain negatiboa. 
Prozesua ez da guztiz berdina Darapti modurako (eta honekin legez gertatzen da Felapton and Fesapo jatorrizko modu aristotelikoekin):

Darapti: Amp, Ams, beraz Isp nahiz Ips.

$$
\begin{aligned}
& \underline{\mathrm{P} \leftarrow \mathrm{M}} \quad \mathrm{M} \rightarrow \mathrm{S} \\
& \underline{\mathrm{P} \leftarrow \mathrm{M} \rightarrow \mathrm{S}}
\end{aligned}
$$

SYLL sisteman ez dago ondoriorik baldin gehitzen ez badugu («M») arau hau:

$$
\leftarrow \mathrm{M} \rightarrow \text { bihurtzen da } \leftarrow \bullet \rightarrow \text {. }
$$

Horrela eginez, ondorioztapenak honelaxe jarraitzen du:

$$
\mathrm{P} \leftarrow \bullet \rightarrow \mathrm{S}
$$

Gehikuntza honekin ere, aldea dago SYLLen eta hemen proposaturiko sistema intentsionalen artean: «M» arau berriak ahalbidetzen digu ondorio zuzenak eskuratzea SYLL sisteman Darapti, Felapton eta Fesapo moduetarako, baina ez da aski Bamalip moduaren ondorio partikularra lortzeko (zeinaren irudikatzea ezin bereiz baitaiteke Barbari moduarenetik). Bamalip/Barbari bereizketa OIL eta OILER sistemetan baino ezin ispila daiteke. Horrek esan nahi du nolabaiteko faktore sakon batek, irudikatzean bertan inplementatuak, hurbilago egiten dituela sistema hauek jatorrizko silogistika aristotelikotik.

\section{Ondorioak eta gerorako lana}

Erakutsi dut badaudela bideak Euler zirkuluez interpretazio intentsionalaren pean baliatzeko. Trataera estentsionaletarako arazotsua den onartze existentziala guztiz naturala zaio ikuspegi intentsionalari: kontzeptu baten existentzia ukaezina da hura etiketatu den bezain pronto. Artikulu honetan proposaturiko sistemek egokiro atzematen dute jatorrizko silogistika aristotelikoa (geroago 4. irudi silogistikoan sartu ziren zeharkako moduak barne), baina kanpoan utziz geroago ere gehitu ziren mendeko moduak. Trataera estentsionalek ezin dute hori egin. Neutralagoa den SYLL sistemak ere huts egiten du zeharkako moduetako bat irudikatzerakoan, nahiz arau sintaktiko berri batez hornitu.

Interesgarria litzateke enpirikoki aztertzea proposamen intentsionalok, EUL bezalako sistemekin egin den eran. 


\section{Erreferentzia bibliografikoak}

BASSLER, O. Bradley (1998), «Leibniz on Intension, Extension, and the Representation of Syllogistic Inference». Synthese 116: 117-139.

Couturat, Louis (1961), La Logique de Leibniz, d'après des documents inèdits. Hildesheim: Olms Verlag.

Gergonne, Joseph D. (1817), «Essai de dialectique rationelle». Annuales de Mathematiques pures et apliquées 7: 189-228.

Johnson-Laird, Philip N. (1983), Mental Models: Towards Cognitive Science of Language, Inference, and Consciousness. Cambridge, MA: Harvard University Press.

Mineshima, Koji; OKadA, Mitsuhiro; Sato, Yuri eta TAKEMURA, Ryo (2008), «Diagrammatic Reasoning System with Euler Circles: Theory and Experiment Design». In Gem Stapleton; John Howse eta John Lee (arg.), Diagrammatic Representation and Inference. Proceedings of the $5^{\text {th }}$ International Conference, Diagrams 2008, 188-205. Berlin: Springer.

Mineshima, Koji; OKada, Mitsuhiro eta Takemura, Ryo (2012), «A Diagrammatic Inference System with Euler Circles». Journal of Logic, Language and Information, vol. 21, 3: 365-391.

PaGnan, Ruggero (2013), «Syllogisms in Rudimentary Linear Logic, Diagrammatically». Journal of Logic, Language and Information, vol. 22, 1: 71-113.

SATo, Yuri (2013), The Cognitive Efficacy of Diagrammatic Representations in Logical Reasoning. PhD Thesis, Keio University.

SATo, Yuri; Mineshima, Koji eta TAKEMURA, Ryo (2010), «The Efficacy of Euler and Venn Diagrams in Deductive Reasoning: Empirical Findings». In Ashok K. Goel; Mateja Jamnik eta N. Hari Narayanan (arg.), Diagrammatic Representation and Inference. Proceedings of the $6^{\text {th }}$ International Conference, Diagrams 2010. Berlin: Springer, 6-22.

SATo, Yuri; Mineshima, Koji eta TaKemura, Ryo (2011), «Interpreting Logic Diagrams: a Comparison of two Formulations of Diagrammatic Representations». Proceedings of 33rd Annual Conference of the Cognitive Science Society: 2182-2187. Austin, TX: Cognitive Science Society.

Stapleton, Gem (2005), «A Survey of Reasoning Systems Based on Euler Diagrams». In Peter Rodgers (arg.), Euler Diagrams 2004. ENTCS (vol. 134). Amsterdam: Elsevier, 127-151.

StenNing, Keith eta Oberlander, Jon (1995), «A cognitive theory of graphical and linguistic reasoning». Cognitive Science 19: 97-140. 